\title{
A IDENTIFICAÇÃO DAS CATEGORIAS LEXICAIS V(ERBO) E N(OME) A PARTIR DE CATEGORIAS FUNCIONAIS
}

\section{THE IDENTIFICATION OF LEXICAL CATEGORIES V(ERB) AND N(OUN) FROM FUNCTION CATEGORIES ${ }^{1}$}

\author{
Sabrina Anacleto Teixeira ${ }^{2}$ \\ Maria Cristina Lobo Name
}

RESUMO: Investigamos o processo inicial de categorização de palavras pertencentes às categorias lexicais $(\mathrm{N})$ ome e $(\mathrm{V})$ erbo. Nossa hipótese é que pistas distribucionais presentes no continuum da fala, como a coocorrência entre determinantes e nomes e entre pronomes e verbos, podem guiar os bebês nesse processo. Bebês de 13 meses adquirindo o português brasileiro (PB) participaram de uma atividade em que pseudopalavras foram apresentadas antecedidas por determinantes ou pronomes e testadas em novos enunciados congruentes ou incongruentes ao padrão familiarizado. Os resultados são discutidos com base em uma perspectiva teórica que visa a conciliar um tratamento psicolinguístico para a aquisição da linguagem (Bootstrapping Fonológico) com uma concepção minimalista para aquisição de língua natural (Programa Minimalista). PALAVRAS-CHAVE: Categorização. Determinantes. Pronomes. Nomes. Verbos.

\begin{abstract}
We investigate the early stages of word categorization to $\mathrm{N}$ (oun) or $\mathrm{V}(\mathrm{erb})$ lexical categories. Our hypothesis is that distributional cues in the input such determiner-noun and pronounverb co-occurrences guide infants in this process. In an experiment, 13-month-old babies acquiring Brazilian-Portuguese were presented to pseudowords preceded by determiners or pronouns and were tested with new stimuli congruent or incongruent to familiarized pattern. We
\end{abstract}

\footnotetext{
${ }^{1}$ Este trabalho foi desenvolvido no âmbito do Projeto CNPq no. 401510/2010-7. Edital Universal Humanas.

${ }^{2}$ Universidade Federal de Juiz de Fora (UFJF), Núcleo de Estudos em Aquisição da Linguagem e Psicolinguística (NEALP), Mestre em Linguística. Email: sat.30@hotmail.com.

${ }^{3}$ Universidade Federal de Juiz de Fora (UFJF), Núcleo de Estudos em Aquisição da Linguagem e Psicolinguística (NEALP). Pesquisadora do CNPq. Professora Adjunta de Linguística. Email: cristina.name@ufjf.edu.br-HTTP:/www.ufjf.br/nealp.
} 
discuss our results in light of a theoretical approach that aims at conciliating a psycholinguistic model for language acquisition (Phonological Bootstrapping) and a linguistic theory (Minimalist Program).

KEYWORDS: Categorization. Determiners. Pronouns. Nouns. Verbs. 


\section{A IDENTIFICAÇÃO DAS CATEGORIAS LEXICAIS V(ERBO) E N(OME) A PARTIR DE CATEGORIAS FUNCIONAIS}

\section{INTRODUÇÃO}

A pesquisa em aquisição lexical se depara com o problema da identificação de palavras no fluxo da fala e do reconhecimento de categorias lexicais pela criança. Ainda que se assuma uma capacidade inata para a aquisição de uma língua natural, faz-se necessário entender como o bebê segmenta os enunciados que ouve em unidades menores, como palavras, e relaciona esses elementos a representações de entidades ou conceitos, agrupando-os em diferentes conjuntos. Em outros termos, procura-se entender como a criança mapeia elementos lexicais a categorias, como N(ome), V(erbo) etc., a partir da exposição a um fluxo contínuo da fala.

Categorias sintáticas se apresentam regularmente distribuídas nas sentenças por exemplo, mesmo havendo alguma variação, nomes ocorrem num mesmo ambiente linguístico, antecedido de determinante. Além disso, outras regularidades podem facilitar a identificação de categorias lexicais, tais como padrões de coocorrência entre elementos e relações de concordância manifestas através de variação morfofonológica.

Diversos autores têm defendido uma abordagem computacional para dar conta das etapas iniciais da aquisição da linguagem, segundo a qual mecanismos estatísticos e de abstração de padrões seriam recursos disponibilizados precocemente (CHEMLA et al., 2009; MARCUS et al., 1999; MINTZ, 2003, 2006; NEWPORT \& ASLIN, 2004). Peña e colaboradores (2002) defendem dois tipos de computação: (a) estatística para segmentar a fala em unidades menores; e (b) não estatística para identificar e generalizar regularidades gramaticais - um processo dependente de inspeção da memória e de projeção de generalizações. Marcus e colaboradores (1999) consideram dois tipos de mecanismos de aprendizagem: um de tratamento estatístico de informações e outro que lidaria com abstração de "regras algébricas", representando relações entre categorias.

Neste artigo, focalizaremos o papel de determinantes e pronomes no início da aquisição lexical. Apresentaremos os resultados de uma atividade experimental que investiga o processo inicial de categorização de palavras pertencentes às categorias lexicais $\mathrm{N}$ ou $\mathrm{V}$ por bebês de 13 meses adquirindo o português brasileiro (PB). Buscamos, nesse estudo, verificar se pistas distribucionais presentes no continuum 
sonoro, como a presença dos itens funcionais determinantes e pronomes, podem guiar os bebês nesse processo. Estudos semelhantes já foram conduzidos em outras línguas (HÖHLE et al. 2004 - em alemão; SHI \& MELANÇON, 2010 - em francês canadense), mas são inéditos com crianças adquirindo o PB.

Nosso estudo assume o modelo de Bootstrapping Fonológico (MORGAN \& DEMUTH, 1996; CHRISTOPHE et al., 1997), segundo o qual propriedades da fala sinalizam a estrutura sintática subjacente e podem ser facilitadoras da identificação de elementos lexicais. Além disso, é compatível com a concepção minimalista de faculdade da linguagem (HAUSER, CHOMSKY \& FITCH, 2002), já que, nessa proposta, o sistema computacional (FLN - Faculdade da Linguagem no sentido estrito) faz interface com outros sistemas cognitivos - sistema articulatório-perceptual e sistema conceitual-intencional - formando, juntos, a Faculdade da Linguagem em sentido amplo (FLB). Desse modo, pode-se assumir a aquisição de uma língua natural a partir dessas interfaces, conciliando, portanto, o modelo gerativista com um modelo de processamento (cf. CORRÊA, 2011; CORRÊA \& AUGUSTO, 2006, 2012).

O artigo está organizado em quatro seções, além desta introdução. Na primeira seção, caracterizamos brevemente os itens funcionais e discutimos sua importância na aquisição de uma língua, tanto do ponto de vista de uma teoria linguística quanto do ponto de vista do processamento; na segunda seção, discutimos particularmente o processo inicial de categorização de itens lexicais pela criança, apresentando trabalhos que apontam o uso de determinantes e pronomes para tratar distintamente os elementos que os seguem; a última seção trata da atividade experimental desenvolvida, assim como da discussão dos resultados. Por fim, concluímos o artigo, retomando a perspectiva teórica adotada e destacando os pontos que julgamos importantes.

\section{A IMPORTÂNCIA DOS ITENS FUNCIONAIS}

Do ponto de vista perceptual, os itens funcionais se distinguem dos itens lexicais por suas propriedades fonéticas, prosódicas e distribucionais. Tendem a apresentar um número mínimo de sílabas, são preferencialmente átonos e, geralmente, se realizam por meio de fones fracos. Além disso, são altamente frequentes e têm distribuição característica, tornando-se previsíveis no contexto sintático. Por outro lado, os itens lexicais não obedecem a um padrão fônico característico, existem em grande número, com frequência variada, não sendo, portanto, previsíveis em função do contexto sintático.

Essas características estão presentes no input ao qual a criança tem acesso e, a partir do momento em que o bebê é sensível a essas características, poderia começar a agrupar os itens de sua língua separadamente, levando a uma distinção preliminar entre categorias lexicais e funcionais. $O$ conhecimento das categorias rudimentares (funcionais versus lexicais), de acordo com Morgan, Shi e Allopenna (1996), poderia ajudar as crianças em vários processos sintáticos e semânticos posteriores, como:

- Mapeamento do significado das palavras, pois se a criança sabe quais palavras do discurso pertencem às classes fechadas e quais pertencem às classes abertas, o número de possibilidades de mapeamento é reduzido;

- Delimitação da estrutura dos sintagmas da sentença. Por exemplo, se os itens funcionais ocorrem no início ou no final dos sintagmas em uma dada língua, a 
partir do reconhecimento desse padrão, a criança teria facilidade em delimitar as fronteiras dos sintagmas;

- Facilitação de classificações mais refinadas, em subconjuntos dentros das classes abertas, já que categorias lexicais podem ser identificadas mais eficientemente através da atenção à coocorrência de determinados itens funcionais e itens lexicais.

Esse último ponto é importante para nosso estudo. De maneira geral, no PB, nomes são antecedidos por determinantes (uma bola, esse carro etc.), e o sujeito dos verbos pode ser um pronome (eu corro, ele viajou etc.). A coocorrência desses elementos não é obrigatória - podemos, por exemplo, ter adjetivos antes de $\mathrm{N}$ ("que grande bagunça!...") e sintagmas antes de V ("essa menina adora leite") - mas é frequente, e poderia ser uma pista para a identificação da categoria a que pertence um dado item. Em casos de homofonia - como, a pinta / ela pinta - só sabemos que se trata de um nome no primeiro caso e de um verbo no segundo em função dos itens que os antecedem. Defendemos, pois, que a presença de determinados itens funcionais determinantes ou pronomes - poderia guiar bebês adquirindo o PB a distinguir as palavras pertencentes às categorias lexicais $\mathrm{N}$ ou $\mathrm{V}$. No entanto, para que tais distinções possam ser possíveis, os bebês devem ser sensíveis às propriedades desses itens funcionais.

Trabalhos em diferentes línguas, como os de Shady (1996) e Shafer et al. (1998) no inglês, e Höhle \& Weissenborn (1998 e 2003) no alemão, indicam a sensibilidade de bebês em torno de um ano às propriedades dos itens funcionais de maneira geral. Além disso, alguns trabalhos trazem evidências da sensibilidade a uma subclasse dos itens funcionais: os determinantes, como Höhle \& Weissenborn (2000) no alemão, Shi, Werker \& Cutler (2003) no inglês e Name (2002) no PB.

Os itens funcionais também têm um importante papel na teoria linguística gerativista. Para o Programa Minimalista (CHOMSKY, 1995), os elementos do léxico são compostos por um conjunto de traços, sendo a variação entre as línguas consequência da valoração dos traços formais da língua. Tais traços codificam as informações a serem acessadas e usadas pelo sistema computacional humano. Em outras palavras, a variação das línguas seria consequência dos traços do léxico.

Os valores dos traços formais que definem os parâmetros das línguas estariam associados às categorias funcionais e representariam no léxico aquilo que se apresenta de forma sistemática na interface fônica. O reconhecimento dos itens funcionais, dessa forma, permitiria o reconhecimento de um número mínimo de traços formais da língua, os quais, mesmo subespecificados, ajudariam na classificação de membros das classes lexicais dentro de uma categoria.

A concepção de faculdade da linguagem assumida pelo Programa Minimalista (HAUSER, CHOMSKY \& FITCH, 2002) se mostra promissora para o entendimento do processo de aquisição lexical que defendemos. A Faculdade da Linguagem em sentido amplo (FLB) inclui os sistemas de desempenho (sistema sensório-motor e sistema intencional-conceptual) e a Faculdade da Linguagem em sentido estrito (FLN), essa última composta de um sistema computacional universal que deriva expressões linguísticas a partir dos elementos do léxico interpretáveis nos sistemas de desempenho.

Diante dessa concepção de faculdade de linguagem, como afirmam Corrêa e Augusto (2012), cabe à criança, provida de um sistema computacional universal e inato, construir o léxico e identificar os traços formais e os valores que lhes são atribuídos na 
sua língua. Assim, para que a aquisição de uma língua se torne viável, a criança teria de partir do pressuposto de que pistas prosódicas e padrões recorrentes na interface fônica sinalizam informações a serem tomadas como gramaticalmente relevante. Em outras palavras, a criança teria de ser sensível a tais pistas e padrões e processar os estímulos linguísticos a que tem acesso de modo e identificar as propriedades - os traços relevantes de sua língua.

Para dar conta do processamento dos enunciados pela criança, lançamos mão da hipótese do Bootstrapping Fonológico (MORGAN \& DEMUTH, 1996; CHRISTOPHE et al., 1997), segundo a qual a análise puramente fonológica do sinal acústico da fala permitiria à criança o desencadeamento da aquisição do léxico e da sintaxe da língua de seu meio. Pistas prosódicas seriam usadas pelo bebê a fim de segmentar o contínuo de fala em unidades prosódicas menores. O início da constituição de um léxico se daria com base nessas representações pré-lexicais prosodicamente segmentadas. Em seguida, um conjunto de informações permitiria extrair dessas representações itens lexicais e funcionais, para a constituição de um léxico. Note-se que esse modelo defende processos diferentes para a identificação dos itens do léxico e, consequentemente, sua classificação em categorias distintas. Frequência de ocorrência e padrão fônico facilitariam a percepção dos itens funcionais, e sua representação estaria diretamente ligada ao processamento da estrutura sintática. Quanto aos itens lexicais, propriedades como regularidade distribucional, restrições fonotáticas, padrão silábico etc. seriam fontes para seu reconhecimento, assim como relações de coocorrência com itens funcionais. A figura abaixo representa o processamento linguístico em seus estágios iniciais, de acordo com a hipótese do Bootstrapping Fonológico.

Figura 1 - Modelo dos estágios iniciais do processamento dos estímulos pelo bebê, de acordo com a Hipótese do Bootstrapping Fonológico

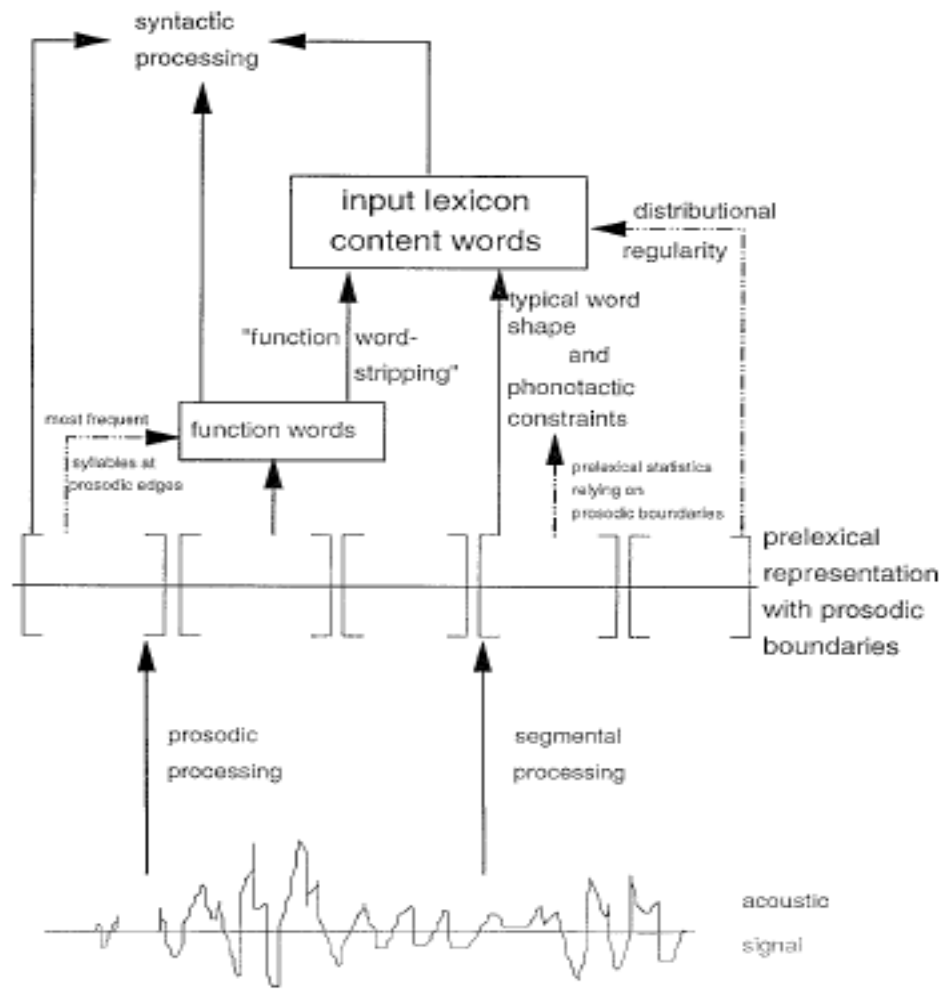

Fonte: CHRISTOPHE et al., 1997 
Dessa forma, assumindo-se uma conciliação entre um modelo de língua e um modelo de processamento (cf. CORRÊA, 2011; CORRÊA \& AUGUSTO, 2006, 2012), no processo de aquisição da linguagem, o bebê teria de identificar na interface fônica o que há de regular, sistemático, baseando-se na frequência, em regularidades e padrões prosódicos e fonéticos. A partir da identificação desses padrões pelo bebê, haveria a formação de um léxico mínimo, contendo elementos de categorias lexicais e funcionais subespecificados, com um número mínimo de traços formais. Esse léxico mínimo desencadearia o parsing sintático inicial e viabilizaria o funcionamento do Sistema Computacional. Análises estatísticas e mecanismos de abstração e generalização também são recursos precocemente disponíveis e explorados por bebês no processo de categorização de elementos lexicais (cf. MARCUS et al., 1999; PEÑA et al., 2002).

\section{A CATEGoRIZAÇÃo de ITENS LEXICAIS A PARTIR DE DETERMINANTES E PRONOMES}

Nesse estudo, assumimos a categorização como o processo inicial de classificação dos elementos das classes abertas em subgrupos - N(ome), V(erbo), etc. Defendemos que essa primeira classificação é realizada precocemente, antes mesmo de o bebê produzir as primeiras palavras. Esse processo seria um dos primeiros passos para a constituição do léxico, ainda com traços subespecificados, e as classificações de nível semântico seriam realizadas posteriormente, a partir da vivência sistemática da criança em situações de interação com outras pessoas e com o mundo.

No que tange à importância dos itens funcionais para a categorização dos itens lexicais, podemos destacar os trabalhos de Mintz (2006), que encontrou evidências da categorização de verbos em inglês a partir de elementos funcionais que antecedem e sucedem os itens lexicais; de Höhle et al. (2004) e Shi e Melançon (2010) que apontam para a categorização de nomes em alemão e francês, respectivamente, baseada na informação do determinante, e de Bagetti (2009) que evidencia o reconhecimento das classes de palavras homófonas do PB em função dos itens funcionais (determinantes e pronomes) que antecedem a palavra.

Höhle e colaboradores (2004) investigaram se a presença dos determinantes e dos pronomes antes das pseudopalavras ajudariam as crianças na categorização dessas pseudopalavras como pertencentes às categorias $\mathrm{N}$ e $\mathrm{V}$. Os autores realizaram uma atividade experimental com crianças divididas em duas faixas: crianças entre 12 e 13 meses e crianças entre 14 e 16 meses.

Os estímulos utilizados foram duas pseudopalavras (glamm e pronk), um artigo indefinido (ein, "uma") e um pronome pessoal sujeito de terceira pessoa (sie, "ela"). Na fase de familiarização, as crianças foram divididas em dois grupos: o grupo 1 ouviu as pseudopalavras antecedidas pelo artigo indefinido e o grupo 2 ouviu as pseudopalavras antecedidas pelo pronome. Na fase de teste, os estímulos eram compostos pelas mesmas pseudopalavras colocadas em pequenas frases, porém antecedidas por pronomes e determinantes diferentes daqueles usados na fase de familiarização ${ }^{4}$.

\footnotetext{
${ }^{4}$ De acordo com os autores, os estímulos do teste eram compostos por sentenças, em que as pseudopalavras eram antecedidas por determinantes e pronomes diferentes daqueles apresentados na fase de familiarização. No entanto, analisando os estímulos completos retirados no site http://www.infancyarchives.com, observamos que, das 12 frases com determinante, quatro têm adjetivos
} 
Se os itens funcionais ajudam as crianças na categorização das pseudopalavras, esperava-se que o grupo 1 estranhasse as sentenças com as pseudopalavras antecedidas por pronomes, pois categorizaram glamm e pronk como nome; e que o grupo 2 estranhasse as sentenças com as pseudopalavras antecedidas por determinantes, pois categorizaram glamm e pronk como verbo.

Dentre as crianças de 12 e 13 meses, não houve diferença significativa no tempo médio de escuta entre as condições congruente e incongruente, tanto no grupo familiarizado com o determinante (média de $6.41 \mathrm{sec}$ vs. $6.54 \mathrm{sec}$, respectivamente), quanto no grupo familiarizado com o pronome (média de $6.88 \mathrm{sec}$ vs. $6.65 \mathrm{sec}$, respectivamente). Tais resultados, portanto, não apresentaram evidência do uso dos determinantes e pronomes na categorização de nomes e verbos por crianças de 12 a 13 meses.

Com as crianças mais velhas, de 14 a 16 meses, os pesquisadores obtiveram resultados diferentes. As crianças familiarizadas com determinante ouviram, em média, mais tempo as passagens incongruentes $(7.90 \mathrm{sec}$ vs.6.95 sec) e essa diferença foi estatisticamente significativa $(\mathrm{t}(23)=2.86, \mathrm{p}<0.01)$. Já as crianças familiarizadas com pronomes não apresentaram diferença relevante entre o tempo médio de escuta das duas condições (congruente: $6.14 \mathrm{sec}$ vs. Incongruente: $6.22 \mathrm{sec} ; \mathrm{t}(23)=0.21, \mathrm{p}=0.83$ ). Observamos que as crianças familiarizadas com determinantes ouviram por mais tempo as sentenças incongruentes, demonstrando estranhamento para as pseudopalavras categorizadas como nome em contextos verbais; no entanto, as crianças familiarizadas com pronomes não preferiram nem um nem outro tipo de sentença, não demonstrando estranhamento da classe da pseudopalavra. Tais resultados sugerem que as crianças, entre 14 e 16 meses, usam a pista dos determinantes para categorizar palavras novas como nomes, mas não usam a pista dos pronomes para a categorização dos verbos.

Segundo os autores, uma possível explicação para o resultado é o comportamento distinto do artigo indefinido e do pronome pessoal sujeito no input, uma vez que a coocorrência entre o artigo e os nomes é mais constante e previsível do que a relação entre o pronome e os verbos. Além disso, a ordem livre do alemão permite que o pronome sujeito seja seguido por um determinante, um nome, um sintagma preposicional ou um advérbio, o que pode dificultar a identificação da relação entre pronome e verbo. Consideramos também que o tipo de sentença usada nos testes possa ter contribuído para o resultado não significativo do grupo de crianças familiarizadas com o pronome.

O trabalho de Shi e Melançon (2010) também teve por objetivo averiguar se o uso de pronomes e determinantes pode ajudar as crianças na categorização de palavras novas como verbos e nomes. Apesar de o objetivo ser o mesmo do trabalho de Höhle e colaboradores (2004), esse trabalho propôs uma atividade um pouco diferente. O experimento foi mudado, para que na fase de teste fossem usados sintagmas menores, formados apenas pelo item funcional e pela pseudopalavra.

A atividade experimental utilizou a Técnica do Olhar Preferencial. Os participantes foram crianças de 14 meses adquirindo o francês canadense. Essa idade foi escolhida em virtude do trabalho de Höhle et al. (2004), citado anteriormente, o qual obteve resultados de categorização de nomes com bebês dessa idade.

Para a composição dos estímulos, duas pseudopalavras foram criadas - mige e crale - e foram utilizados três determinantes - des, artigo indefinido feminino ou

entre o determinante e a pseudopalavra e das 12 sentenças com pronomes, apenas uma tem um pronome pessoal na posição de sujeito, as outras possuem um DP. 
masculino plural, ton, pronome possessivo "teu/seu"; le, artigo definido masculino singular "o" - e três pronomes - je, "eu"; $i l$, "ele"; tu, "tu/você". Na fase de familiarização, criaram-se dois grupos de crianças: o grupo 1 ouviu as quatro combinações de determinantes (ton e des) com as pseudopalavras (mige e crale) e o grupo 2 ouviu as quatro combinações de pronomes (je e $i l$ ) com as mesmas pseudopalavras (mige e crale).

$\mathrm{Na}$ fase de teste, as crianças dos dois grupos foram testadas com os mesmos estímulos, contendo sintagmas formados com o determinante (le) e o pronome $(t u)$ e as pseudopalavras (mige e crale). Para o grupo 1, as combinações do determinante (le) e as pseudopalavras eram congruentes, pois as pseudopalavras estavam em contexto de nome, como na familiarização; já as combinações do pronome (tu) com as pseudopalavras eram incongruentes, uma vez que as pseudopalavras estavam em contexto de verbo. O inverso acontecia para o grupo 2: as combinações do determinante (le) e as pseudopalavras eram incongruentes, pois as pseudopalavras estavam em contexto de nomes, diferente da familiarização, em que estavam em contexto de verbo, e as combinações do pronome $(t u)$ com as pseudopalavras eram congruentes, pois as pseudopalavras estavam no mesmo contexto da familiarização.

Se as crianças nessa idade percebem as classes das palavras novas, baseadas na informação dos itens funcionais que as antecedem, elas estranhariam os sintagmas incongruentes em relação aos da fase de familiarização. Com efeito, as crianças familiarizadas com determinante escutaram mais tempo as passagens incongruentes (média de $7.671 \mathrm{sec}$ vs $5.393 \mathrm{sec}$ para as passagens congruentes), apresentando uma diferença estatisticamente significativa $(\mathrm{t}(15)=2.593, \mathrm{p}=0.02)$. No entanto, as crianças familiarizadas com pronomes, tal como ocorreu com as crianças alemãs, não apresentaram diferença estatisticamente significativa entre os tempos médios de escuta das duas condições (congruente: $7.626 \mathrm{sec}$ vs. incongruente: $7.674 \mathrm{sec} ; \mathrm{t}(15)=0.064, \mathrm{p}$ $=0.95$ ).

Diante desses resultados, percebemos que as crianças do grupo 1 ouviram por mais tempo os sintagmas incongruentes, demonstrando estranhamento diante da ocorrência da pseudopalavra, apresentada na fase de familiarização como nome, num contexto em que apenas verbos aparecem. Por outro lado, o grupo 2 não teve preferência por um ou outro tipo de sintagma. Visto isso, podemos dizer que as autoras obtiveram evidência de que os determinantes ajudam na categorização de nomes, mas não do uso dos pronomes na categorização dos verbos. A justificativa dada pelas autoras para essa diferença foi a relação adjacente entre determinantes e nomes, que parece ser mais constante do que a relação de adjacência entre pronomes diante de verbos, pois os verbos podem ser antecedidos também por NP. Além disso, no francês, muito raramente um nome aparece sem ser antecedido por um determinante.

Quanto à categorização de nomes e verbos em $\mathrm{PB}$, podemos citar o trabalho de Bagetti (2009), cujo objetivo foi verificar se a criança analisa diferencialmente elementos lexicais homófonos que pertencem a categorias gramaticais diferentes $(\mathrm{N}$ ou $\mathrm{V}$ ), em função da análise do item funcional (determinante ou pronome) que os antecede ${ }^{5}$.

A autora elaborou um experimento com a técnica de Fixação Preferencial do Olhar realizado com oito crianças com idades entre 17 e 23 meses (média de idade de

\footnotetext{
${ }^{5} \mathrm{~A}$ autora também buscava verificar em que medida a presença de um afixo, morfologicamente marcado em relação a tempo (passado), afetaria a análise sintática pela criança. Contudo, esse ponto não será detalhado, pois foge ao escopo do artigo.
} 
21 meses). Tal experimento apresentava estímulos auditivos e visuais, tendo por alvos palavras homófonas $\mathrm{N}$ ou $\mathrm{V}$ - por exemplo, enunciados como "o pinto na mesa" ou "eu pinto a mesa" e imagens como um pintinho em cima da mesa e uma menina pintando a mesa.

Durante o teste, a criança ouvia um estimulo auditivo e apareciam duas imagens, uma com a palavra alvo em situação de nome e outra, em situação de verbo. Verificava-se, então, em que imagem a criança fixava mais tempo o olhar. Se a criança conseguia identificar a categoria gramatical da palavra alvo em função dos determinantes ou dos pronomes, esperava-se que a fixação do olhar fosse para a imagem que representava a palavra na categoria gramatical ouvida no estímulo auditivo. Por exemplo, se a criança ouvia a sentença eu pinto a mesa e reconhecesse a palavra alvo, pinto, como verbo em função da presença pronome $e u$, ela fixaria seu olhar durante mais tempo para a imagem em que a menina está pintando a mesa.

Durante a escuta das palavras pertencentes à categoria $\mathrm{N}$, as crianças olharam em média 653.29 cs para a imagem correspondente ao nome (situação congruente com a categoria gramatical) e em média 351 cs para a imagem correspondente ao verbo (situação não congruente com a categoria gramatical). Durante a escuta de palavras pertencentes à categoria $\mathrm{V}$, as crianças fixaram seu olhar em $571.04 \mathrm{cs}$ para as imagens correspondentes ao verbo (situação congruente com a categoria gramatical) e em média 497.12 cs para figuras com situação correspondente ao nome (situação não congruente com a categoria gramatical). Observou-se que, nas duas condições, as crianças preferiram fixar o olhar nas imagens correspondentes à classe gramatical com diferença estatisticamente significativa ( $\mathrm{p}=01$ para a condição $\mathrm{N}$ e $\mathrm{p}=0.02$ para a condição $\mathrm{V}$ ). Esses resultados sugerem que as crianças são sensíveis às categorias $\mathrm{N}$ e V com base na informação dos elementos funcionais (pronomes e determinantes).

Em suma, o trabalho de Bagetti (2009) indica que palavras homófonas podem ser analisadas diferentemente quanto aos seus traços categoriais, com base na distinção entre pronomes e determinantes, por crianças brasileiras em torno de 21 meses.

Os trabalhos mencionados apresentam evidências robustas da importância dos itens funcionais para a categorização de palavras por bebês a partir dos 14 meses de vida, sobretudo para o uso do determinante na categorização dos nomes. Percebemos que os primeiros trabalhos evidenciam a sensibilidade dos bebês aos traços distribucionais das duas categorias, $\mathrm{N}$ e $\mathrm{V}$, em função da informação dos itens funcionais; o trabalho em PB sugere a sensibilidade de crianças a partir de 17 meses, não apenas aos traços distribucionais das duas categorias, mas também aos traços sintático-semânticos dos nomes e verbos.

A partir desses resultados, buscamos investigar o processo de categorização por crianças adquirindo o PB. Nossas hipóteses partem da ideia de que os itens funcionais - determinantes e pronomes - são pistas utilizadas pelos bebês na categorização de palavras novas como nomes e verbos. $\mathrm{Na}$ próxima seção, apresentaremos a atividade experimental desenvolvida para testar nossas hipóteses, inspirada no experimento realizado por Shi e Melançon (2010). Chamamos a atenção para dois pontos: (1) testamos crianças mais novas do que as testadas em francês e alemão, e obtivemos resultados significativos; (2) diferentemente dos trabalhos anteriores, nossos resultados foram expressivos não apenas na condição "Determinante", mas também, na condição "Pronome". 


\section{ATIVIDADE EXPERIMENTAL 6}

A fim de verificar se bebês aos 13 meses de idade são capazes de categorizar palavras novas com base na informação dos itens funcionais que as antecedem, realizamos uma atividade experimental usando a técnica do Olhar Preferencial. Essa técnica pode ser realizada com crianças de 4 a 18 meses e permite observar a sensibilidade auditiva da criança a uma ou mais propriedades da língua ou a identificação de um determinado elemento/nova palavra no fluxo da fala.

Participaram dessa atividade 16 bebês brasileiros de 13 meses (idade média). As crianças foram familiarizadas com duas pseudopalavras antecedidas por determinantes (para um grupo de crianças) ou por pronomes pessoais sujeito (para o outro grupo). Em seguida, as mesmas pseudopalavras foram apresentadas antecedidas por novos determinantes e pronomes.

Nossas hipóteses são que (1) os bebês aos 13 meses já identificam os determinantes e os pronomes como grupos distintos dentro da categoria dos itens funcionais, e (2) o tipo de item funcional que antecede a pseudopalavra pode ajudar a criança no reconhecimento da classe dessa pseudopalavra.

Com base nessas hipóteses e nos resultados de trabalhos anteriores, nossa previsão é que os bebês escutarão mais tempo os estímulos com padrão diferente daquele apresentado durante a familiarização. Bebês que escutaram as pseudopalavras antecedidas de determinantes deverão estranhar quando as ouvirem acompanhadas de pronomes; por sua vez, bebês familiarizados com os pronomes seguindo as mesmas palavras, estranharão quando as ouvirem antecedidas de determinantes. Em ambos os casos, prevemos um tempo maior de escuta para os estímulos incongruentes ao padrão previamente familiarizado.

\subsection{Método}

\subsubsection{Participantes}

Participaram da atividade experimental 19 bebês brasileiros com idade média de 13 meses. Entretanto, três bebês foram eliminados por inquietação e choro (2) e problemas técnicos durante a sessão (1). Assim, os resultados encontrados são referentes a 16 bebês, dentre os quais dez são do sexo masculino e seis são do sexo feminino, com idades entre $11 \mathrm{~m} 27 \mathrm{~d}$ e $14 \mathrm{~m} 6 \mathrm{~d}$. Os participantes foram divididos em dois grupos, como será detalhado posteriormente. Dessa forma, nove bebês constituíram o Grupo 1 e sete constituíram o Grupo 2. As crianças foram recrutadas pelos pesquisadores do NEALP e não receberam nenhuma retribuição financeira e/ou de outra ordem pela participação na atividade.

\subsubsection{Material}

A elaboração dos estímulos foi baseada no trabalho de Shi e Melançon (2010), que usaram três determinantes (des, artigo indefinido feminino ou masculino plural; ton, pronome possessivo "teu/seu"; le, artigo definido masculino singular "o") e três

\footnotetext{
${ }^{6}$ Pesquisa aprovada no Comitê de Ética em Pesquisa/UFJF, Parecer no. 100/2011.
} 
pronomes (je, "eu"; $i l$, "ele"; $t u$, "tu/você"). Na fase de teste, foram apresentados apenas sintagmas, por exemplo, le crale e le mige.

De forma semelhante, usamos três determinantes - a, uma e essa -, três pronomes pessoais - ele, ela e você - e duas pseudopalavras - piva e dema. Não escolhemos os mesmos determinantes e pronomes do francês por questões teóricas e por questões de adequação às características específicas do PB.

Quanto aos determinantes, selecionamos apenas determinantes no gênero feminino para facilitar a concordância com as pseudopalavras terminadas em -a. Tal terminação representa o padrão de marcação do gênero feminino nos nomes do PB. Optamos por não usar um possessivo no grupo dos determinantes, mas um demonstrativo (essa), já que não é clara a caracterização dos possessivos como determinantes no $\mathrm{PB}^{7}$.

Quanto aos pronomes, por questões de concordância verbal, escolhemos apenas pronomes que concordam com o verbo em terceira pessoa, diferentemente do trabalho em francês que usou pronomes de primeira e segunda pessoa. $O$ francês apresenta variação morfológica na escrita, mas não apresenta diferença na fala; já o PB apresenta variação tanto na escrita quanto na fala, como eu canto e ele canta. $\mathrm{O}$ pronome você, embora se refira à segunda pessoa do discurso, concorda com o verbo na terceira pessoa.

Contrariamente ao francês, o PB admite itens funcionais dissílabos e não apenas monossílabos; isso nos permite usar os determinantes dissílabos uma e essa e os pronomes ele, ela e você.

Outro fator que influenciou a escolha dos itens funcionais usados no experimento foi a frequência. Fizemos uma análise de dados de fala dirigida à criança $\mathrm{e}$ verificamos quais eram os determinantes mais usados nos DPs e quais os pronomes pessoais mais usados na posição de sujeito. Os corpora utilizados foram o Corpus CHILDES (MAC WHINNEY, 2000) $)^{8}$ e dados pertencentes ao Corpus do LAFE Laboratório de Aquisição da Fala e da Escrita da UFPB ${ }^{9}$.

As pseudopalavras foram criadas respeitando o padrão silábico do $\mathrm{PB}$ e iniciadas por consoantes oclusivas. Essas consoantes são as primeiras consoantes adquiridas pela criança e facilitam a manipulação dos dados no PRAAT (BOERSMA E WEENICK, 2008). Além disso, a terminação dessas pseudopalavras remete ao feminino dos nomes e à terceira pessoa do presente dos verbos. Situação semelhante pode ser verificada em palavras homófonas do $\mathrm{PB}$, como dança (que pode ser um nome feminino e um verbo na terceira pessoa do presente). Preferimos não usar palavras reais do PB para que a frequência do uso de uma palavra não influenciasse na categorização feita pela criança.

$\mathrm{Na}$ fase de familiarização, usamos dois determinantes (a e uma) e dois pronomes (ele e ela) e na fase de teste usamos o determinante essa e o pronome você.

\footnotetext{
${ }^{7}$ Os possessivos costumam ser caracterizados como determinantes na literatura. Por exemplo, Radford (1997) sustenta a presença dos possessivos na classe dos determinantes baseado no fato de, em inglês, a presença de o possessivo excluir o uso conjunto de outro determinante. No entanto, em PB, apresentam comportamento diferente, pois podem ser usados junto com outro determinante (ex.: o meu livro está na mesa) e possuem certa mobilidade dentro do sintagma (ex.: aqueles parentes meus vieram do exterior.). Ver Faria (2012) para discussão.

${ }^{8}$ Utilizamos os dados do PB - Florianópolis SC - criados por Leonor Scliar-Cabral.

${ }^{9}$ Dados gentilmente disponibilizados pela profa. Marianne C. B. Cavalcante e publicados na tese de doutorado Da voz à língua: a prosódia materna e o deslocamento do sujeito na fala dirigida ao bebê. IEL/UNICAMP, 1999.
} 
Mudamos os determinantes e os pronomes na fase de teste para verificar se as crianças reconhecem os elementos dos subgrupos de itens funcionais e não apenas reconhecem ou estranham determinado item funcional previamente familiarizado. Na fase de teste, como no experimento em francês, utilizamos apenas sintagmas e não sentenças: isso torna os estímulos menores, facilitando a manutenção da atenção à atividade e, consequentemente, a obtenção de resultados com crianças menores.

Resumindo, os estímulos foram duas pseudopalavras (piva ['piva] e dema ['dẽma]) empregadas em duas condições: nomes - quando antecedidas pelos determinantes ( $a$, uma e essa) - e verbos - quando antecedidas pelos pronomes (ele, ela e você), de acordo com a variável independente "tipo de item funcional que antecede as pseudopalavras", em dois níveis (determinante e pronome).

Tabela 1 - Estímulos usados no experimento

\begin{tabular}{|c|l|l|}
\hline Pseudopalavras & \multicolumn{1}{|c|}{ Det $+\mathbf{N}$} & \multicolumn{1}{|c|}{ Pron + V } \\
\hline \multirow{2}{*}{ Piva } & A piva & Ele piva \\
& Uma piva & Ela piva \\
& Essa piva & Você piva \\
\hline \multirow{2}{*}{ Dema } & A dema & Ele dema \\
& Uma dema & Ela dema \\
& Essa dema & Você dema \\
\hline
\end{tabular}

Os sintagmas foram gravados por uma mulher falante nativa do português. Com o objetivo de produzir uma articulação natural, orientamos para que ela pronunciasse os sintagmas de forma mais natural possível. Para constituição dos estímulos, recortamos no PRAAT os determinantes, os pronomes e as pseudopalavras separadamente; depois, no mesmo programa, juntamos os itens funcionais e as pseudopalavras formando os sintagmas. Entre o determinante/pronome e a pseudopalavra foi acrescentada uma pausa de $100 \mathrm{msec}$ e entre os sintagmas, uma pausa de 1 sec. Além disso, controlamos o contorno prosódico das pseudopalavras usadas de modo que a mesma gravação de cada pseudopalavra fosse usada na condição nome e na condição verbo. Isso possibilitou que não houvesse diferença na prosódia para verbo e nome e que a única diferença entre os estímulos pareados fosse o tipo de item funcional (determinante ou pronome).

\subsubsection{Procedimento}

O experimento se desenvolveu no Laboratório do NEALP da UFJF, usando-se a técnica de Olhar Preferencial. A criança e seu responsável são recebidos pelos pesquisadores em uma antessala, e a criança é convidada a brincar com brinquedos em um tapete emborrachado, enquanto se explica a seu responsável a atividade. Uma vez ambientada, a criança é levada, junto com o responsável, para a sala em que acontece a atividade.

Durante a atividade, a criança fica no colo do responsável em frente a uma tela. O responsável usa fones de ouvido com música durante toda a atividade, de modo que ele não possa ouvir o que a criança vai escutar, evitando qualquer interferência de sua parte. Os pesquisadores permanecem na cabine de controle que fica atrás da sala de 
experimento. Apenas um pesquisador marca o tempo de olhar da criança. Esse monitoramento é feito através da visualização do olhar da criança, disponibilizada pela televisão localizada na cabine de controle, ligada à câmera de filmagem situada na sala de experimento. Cronometramos o tempo de olhar da criança para a imagem apresentada na tela, que corresponde diretamente ao tempo de escuta do estímulo acústico. O tempo de olhar de cada estímulo é marcado através do software Habit ${ }^{10}$.

A técnica de Olhar Preferencial se constitui de quatro fases: pré-teste, familiarização, teste e pós-teste. Entre uma fase e outra e também entre um ensaio e outro, tem-se "entre-fases", denominadas attenttion getter, com a função de atrair a atenção da criança. Em todas as fases, são usados estímulos auditivos e visuais. Os estímulos auditivos são apresentados por meio de um alto-falante, centralizado junto à tela. Quanto aos estímulos visuais, foram criados dois vídeos curtos, apresentados em looping: um para as fases de apresentação dos estímulos linguísticos (pré-teste, familiarização, teste e pós-teste) e o outro para o attention getter.

Por serem mais importantes para avaliar nossas hipóteses, focalizaremos apenas as fases de familiarização e de teste ${ }^{11}$. A familiarização consistiu de um áudio contínuo de dois minutos constituído de sintagmas compostos pela pseudopalavra antecedida pelos determinantes $a$ e uma ou pelos pronomes ele e ela. Para a condição Det $+\mathrm{N}$, construímos 24 sintagmas com o determinante uma (12 sintagmas uma + piva e 12 sintagmas uma + dema $)$ e 22 sintagmas com o determinante $a$ (11 sintagmas $a+$ piva e 11 sintagmas $a+$ dema). Para a condição Pron $+\mathrm{V}$, construímos 24 sintagmas com o pronome ele (12 sintagmas ele + piva e 12 sintagmas ele + dema $)$ e 22 sintagmas com o pronome ela (11 sintagmas ela + piva e 11 sintagmas ela + dema $)$. Esses estímulos foram gravados com diferentes contornos prosódicos e eram iguais nas duas condições, exceto o item manipulado.

Nessa fase, buscamos familiarizar a criança com a classe da pseudopalavra; para isso, as crianças foram divididas em dois grupos: o grupo 1 foi exposto à condição Det $+\mathrm{N}$, na qual as duas pseudopalavras são precedidas pelos determinantes a e uma; o grupo 2 foi exposto à condição Pron $+\mathrm{V}$, em que as mesmas pseudopalavras são precedidas pelos pronomes ele e ela.

Tabela 2 - Comparação entre os estímulos usadas para os grupos 1 e 2 na fase de familiarização

\begin{tabular}{|l|l|}
\hline \multicolumn{1}{|c|}{ GRUPO 1 } & \multicolumn{1}{c|}{ GRUPO 2 } \\
\hline A/Uma piva & Ele/Ela piva \\
A/Uma dema & Ele/Ela dema \\
\hline
\end{tabular}

A fase de teste inicia-se logo após os dois minutos de áudio da fase de familiarização. Para essa fase, utilizamos as mesmas pseudopalavras da fase de familiarização com o determinante essa e com o pronome você. Foram, assim, criados 12 ensaios, cada um contendo seis sintagmas. Metade dos ensaios constituía a condição

${ }^{10}$ Software gratuito (COHEN; ATKINSON; CHAPUT, 2000) usado na técnica de Olhar Preferencial.

11 A fase de pré-teste é um tipo de "aquecimento", em que apresentamos uma pequena história com duração de 16 segundos. No pós-teste, a fim de garantir que a criança se manteve atenta até o final da atividade, apresentamos outra pequena história com duração de aproximadamente 16 segundos. Para detalhes, ver Name (2012). 
Det $+\mathrm{N}$ e era formada pela combinação do determinante essa e das pseudopalavras; a outra metade constituía a condição Pron $+\mathrm{V}$ e era formada pelo pronome você e mesmas pseudopalavras.

Nessa fase, as crianças dos dois grupos são expostas aos mesmos estímulos compostos por duas condições: a condição congruente, que apresenta a mesma categoria gramatical da fase de familiarização e a condição incongruente, que apresenta a categoria gramatical diferente.

Gráfico 1 - Comparação entre os estímulos congruentes versus incongruentes na fase de teste para cada grupo

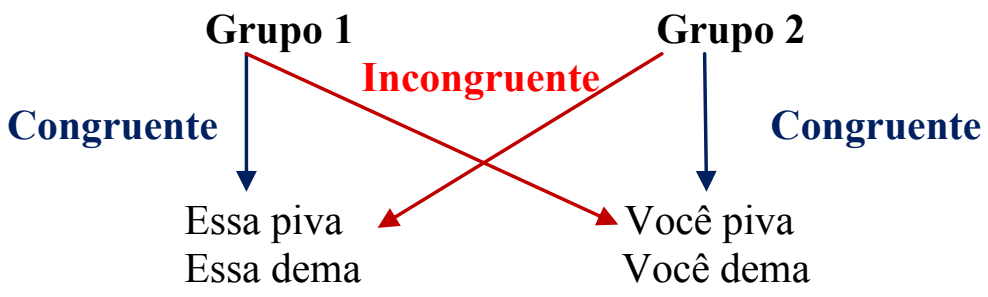

\subsection{Resultados e discussão}

Os resultados de ambos os grupos apontam uma preferência para a condição congruente, indicando que os bebês estranharam quando a palavra familiarizada com elementos de um subconjunto de itens funcionais foi apresentada, no teste, com um elemento de outro subconjunto. As crianças do grupo 1 ouviram a condição congruente por $8,8 \mathrm{sec}$ (tempo médio) e a condição incongruente por 7,0 sec (tempo médio). As crianças do grupo 2 ouviram a condição congruente por 9,81 sec (tempo médio) e a condição incongruente por 7,98 sec (tempo médio). Apresentamos esses resultados no gráfico abaixo:

Gráfico 2 - Comparação das médias totais de tempo de olhar/escuta, em segundos, entre as condições congruente e incongruente dos grupos de crianças familiarizadas com Det $+\mathrm{N}$ e Pron $+\mathrm{V}$

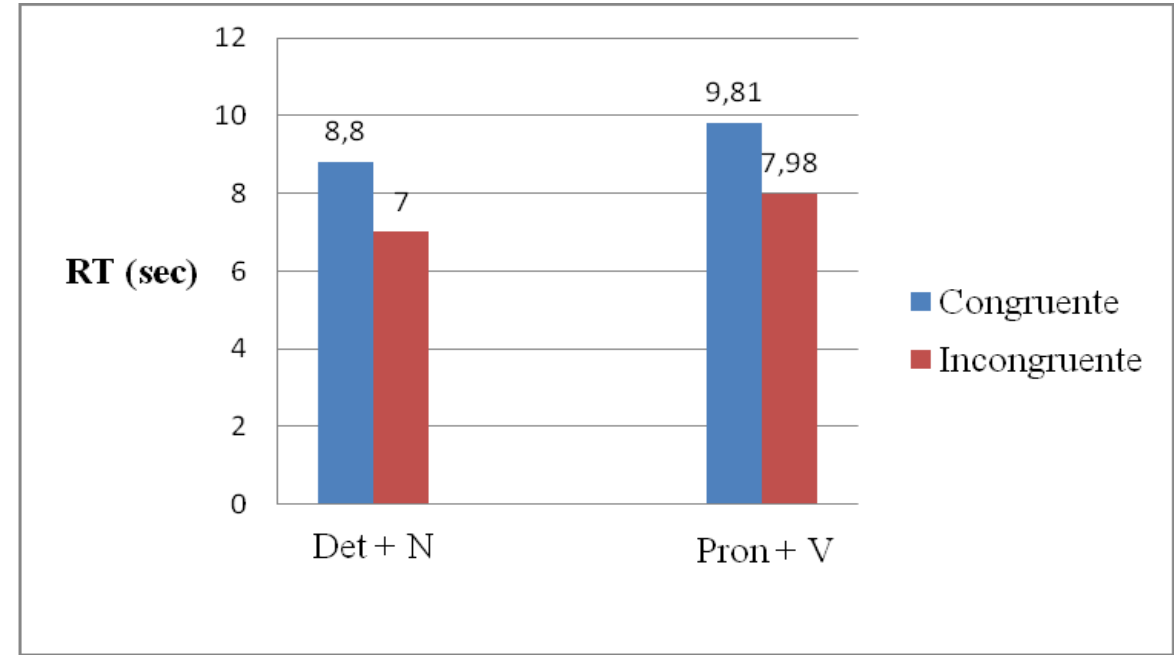


Os dados foram submetidos a uma análise de variância (ANOVA) de medidas repetidas com design fatorial $2 \times 2$. Os fatores verificados foram: Categoria (congruente versus incongruente) como fator entre sujeitos e Familiarização (Det $+\mathrm{N}$ versus Pron + V) como fator dentre sujeitos. Não houve efeito significativo do fator Familiarização: $\mathrm{F}(1,14)=0,192, \mathrm{p}=0.667$. Por outro lado, o efeito do fator Categoria foi significativo: $\mathrm{F}(1,14)=6,17, \mathrm{p}=0,024$. A interação entre o efeito de Categoria e Familiarização não foi significativa $(\mathrm{F}(1,14)=0,085, \mathrm{p}=0.774)$.

Em seguida, um teste $t$ foi feito para analisar o desempenho de cada grupo. Para o grupo familiarizado com Det $+\mathrm{N}$, a média de tempo de olhar/escuta foi maior para a condição congruente, com diferença significativa: $t(8)=2.404, p=0.04$. Para $o$ grupo familiarizado com Pron $+\mathrm{V}$, a média de tempo de olhar/escuta foi maior para a condição congruente, porém a diferença não foi significativa: $t(6)=2,095, p=0.080$.

Os resultados mostram que as crianças familiarizadas com Det $+\mathrm{N}$ consideraram o determinante apresentado no teste da mesma categoria dos determinantes familiarizados. Essa classificação foi uma pista para a categorização das pseudopalavras que seguiam os determinantes. Apesar de o resultado do teste $\mathrm{t}$ das crianças familiarizadas com Pron $+\mathrm{V}$ não ter sido significativo (mas próximo da significância), atribuímos esse resultado ao número reduzido de crianças. Os resultados das médias individuais mostram que houve uma preferência para a condição congruente, uma vez que seis das sete crianças olharam/ouviram mais a condição congruente. Além disso, o efeito do fator Categoria na análise da variância foi significativo. A partir dessas análises, podemos defender que as crianças do grupo 2 consideraram o pronome apresentado no teste do mesmo grupo dos apresentados na fase de familiarização, o que ajudou a categorizar as pseudopalavras que seguiam os pronomes com um grupo distinto das que seguiam os determinantes.

Os resultados apresentados sugerem que bebês com idade média de 13 meses já separam determinantes e pronomes em conjuntos distintos dentro do grupo dos itens funcionais, o que seria um pré-requisito para a categorização da palavra que vem em seguida como $\mathrm{N}$ ou $\mathrm{V}$.

Os trabalhos anteriores realizados com bebês adquirindo o alemão (HÖHLE et al., 2004) e o francês (SHI \& MELANÇON, 2010) só encontraram diferença entre as condições das crianças familiarizadas com Det $+\mathrm{N}$, i.e., as crianças familiarizadas com os determinantes antecedendo as pseudopalavras. Esses resultados indicavam o uso do determinante para a categorização de nome; no entanto, não apresentaram evidências do uso dos pronomes para a categorização dos verbos. Nossos resultados foram compatíveis com a hipótese de que as crianças usam a presença do determinante como pista para a categorização de palavras novas como nomes, visto que a diferença entre as condições do grupo de crianças familiarizadas com determinantes foi estatisticamente significativa. Além disso, temos indícios do uso dos pronomes como pista para a categorização dos verbos; contudo, nossas evidências ainda não são robustas, visto que houve uma diferença perto da significância.

Também podemos observar que, diferentemente dos bebês alemães e franceses - os quais preferiram a condição incongruente -, os bebês brasileiros preferiram a condição congruente, ou seja, olharam/ouviram por mais tempo as condições que apresentavam sintagmas congruentes com os da fase de familiarização. Segundo Roder, Bushnell e Sasseville (2000), a preferência pela familiaridade na fase de teste pode acontecer especialmente quando a exposição aos estímulos familiares foi relativamente breve ou quando a escolha para o teste familiar foi para estímulos semelhantes, mas não 
completamente idênticos aos estímulos apresentados na fase anterior. Além disso, o mesmo autor menciona que a preferência para o familiar poderia refletir uma fase inicial de processamento, enquanto a preferência para os ensaios novos reflete um processamento completo.

Podemos, então, justificar a mudança de preferência baseadas no fato de que nossas crianças são mais novas que as testadas nos trabalhos anteriores, visto que a idade média nos trabalhos anteriores é 14 meses e a idade média do nosso estudo é 13 meses, o que pode indicar que os bebês estariam, talvez, em momento anterior do processo de categorização. Outro fator que pode ter influenciado é o período de exposição, que variou de um experimento para outro. Além disso, os estímulos da condição congruente no teste foram semelhantes, mas não iguais aos apresentados na primeira fase, uma vez que os itens funcionais eram do mesmo subgrupo (determinante ou pronome), mas não os mesmos. Todavia, ressaltamos que há uma discussão na literatura em relação à interpretação a ser dada à preferência do bebê ao tipo de estímulo - novo ou conhecido (ver NAME, 2012). O mais importante é que obtivemos uma diferença estatisticamente significativa na comparação entre a média dos tempos de escuta dos bebês nas duas condições.

\section{CONCLUSÃO}

Os resultados apresentados nesse artigo sugerem que bebês com idade média de 13 meses já separam determinantes e pronomes em conjuntos distintos dentro do grupo dos itens funcionais, o que seria um pré-requisito para a categorização da palavra que vem em seguida como $\mathrm{N}$ ou $\mathrm{V}$. Ainda que tenham sido familiarizadas previamente com as duas pseudopalavras apresentadas durante o teste, as crianças reagiram diferentemente, em função do elemento que as antecedia, que podia fazer parte do mesmo grupo de itens familiarizados ou não. Isso sugere um início de categorização da pseudopalavra pelas crianças, já que estranharam seu uso antecedido por um item "inadequado".

Esse é um resultado inédito para os estudos na aquisição da linguagem, uma vez que os trabalhos anteriores que foram base para nosso trabalho, Höhle et al. (2004) e Shi e Melançon (2010), só encontraram evidências da identificação dos determinantes por crianças para a categorização de nomes.

Além disso, os resultados aqui apresentados foram encontrados com crianças com idade média de 13 meses, diferentes do trabalho de Höhle et al. (2004) que não encontrou evidências com crianças entre 12 e 13 meses. Esse resultado pode ser explicado pelo uso de estímulos menores que permitem o maior controle e atenção de crianças menores.

Em termos teóricos, buscamos explicar a conciliação entre o modelo de língua proposto pelo Programa Minimalista e o modelo psicolinguístico de aquisição da linguagem - Bootstrapping Fonológico. A teoria linguística prevê uma interface entre a FLN e os sistemas conceptuais e perceptuais, e o modelo de processamento admite que a análise fonológica do sinal acústico da fala permitiria à criança iniciar a aquisição do léxico e da sintaxe de sua língua materna. Com a conciliação desses modelos, percebemos que pistas prosódicas e padrões recorrentes na interface fônica sinalizariam informações a serem tomadas como gramaticalmente relevante (cf. CORRÊEA, 2011; CORRÊA \& AUGUSTO, 2006, 2012). 
Dentro dessa perspectiva teórica conciliatória, os itens funcionais são importantes para o desencadeamento da aquisição da linguagem, visto que, com a percepção e a identificação dos itens funcionais no continuum sonoro, ocorre a distinção das categorias funcionais (classe fechada) e lexicais (classe aberta), tornando possível a criação de um léxico mínimo e subespecificado. Esse léxico mínimo seria suficiente para desencadear a inicialização do sistema computacional linguístico. Os resultados da nossa pesquisa indicam que os itens funcionais também são importantes para as especificações dos traços, sobretudo formais, dos elementos do léxico. A identificação de subgrupos dos itens funcionais, como determinantes e pronomes, ajudaria a identificação do traço de categoria dos nomes e dos verbos. Os bebês parecem perceber, por meio da interface fônica, as relações de coocorrência entre itens funcionais e lexicais e através de regras algébricas (cf. MARCUS et al., 1999) começariam a construir a gramática de sua língua.

Buscamos, nesse artigo, apresentar um avanço nos estudos psicolinguísticos acerca da aquisição lexical e de capacidades de abstração e generalização de padrões linguísticos recorrentes na língua, focalizando o processo inicial de categorização lexical por crianças adquirindo o português brasileiro.

\section{REFERÊNCIAS BIBLIOGRÁFICAS}

BAGETTI, T. Um estudo experimental do processamento na interface fônica e da análise sintática inicial: o papel de elementos funcionais na aquisição da linguagem. Tese (Doutorado), PUC RJ, 2009.

BOERSMA, P. \& WEENICK, D. PRAAT: doing phonetics by computer (version: 5.0.25), 2008. Disponível em: http://www.praat.org.

CHEMLA, E., MINTZ, T., BERNAL, S., CHRISTOPHE, A. Categorizing words using 'Frequent Frames': What cross-linguistic analyses reveal about distributional acquisition strategies. Developmental Science, nº 12, p. 396-406, 2009.

CHOMSKY, N. The Minimalist Program. Mass.: The MIT Press, 1995.

CHRISTOPHE, A.; GUASTI, T.; NESPOR, M.; DUPOUX, E.; VAN OOYEN, B. Reflections on phonological bootstrapping: its role for lexical and syntactic acquisition. Language and Cognitive Processes, v. 12, n. 5/6, p. 585-612, 1997.

COHEN, L. B.; ATKINSON, D. J.; CHAPUT, H. H. Habit 2000: A new program for testing infant perception and cognition. (Version 2.2.5c) [Computer software]. Austin: University of Texas, 2000.

CORRÊA, L. M. S. Aquisição e processamento da linguagem: uma abordagem integrada sob a ótica minimalista. Gragoatá. Niterói, 30, p. 55-75, 2011.

CORRÊA, L. M. S. \& AUGUSTO, M. R. A. Computação linguística no processamento on-line: em que medida uma derivação minimalista pode ser incorporada em modelos de processamento? Texto para discussão na sessão Intergts da ANPOLL

(Psicolinguística e Teoria de Gramática), 19-21 de julho de 2006. 
CORREAA, L. M. S. \& AUGUSTO, M. R. A. A aquisição da linguagem no arcabouço minimalista sob uma perspectiva psicolinguística. In: FERRARI-NETO, J.; SILVA, C. R. T. (org.) Programa Minimalista em foco: princípios e debates. Curitiba, PR: Editora CRV, p. 271-300, 2012.

FARIA, F. C. Aspectos Relevantes do Possessivo no Processo de Aquisição do Português Brasileiro. Tese (Doutorado), Universidade Federal de Juiz de Fora, Juiz de Fora, 2012.

HAUSER, M.; CHOMSKY, N.; FITCH, W. T. The Faculty of language: what is it, who has it, and how did it evolve? Science, v. 298, p. $1569-1579,2002$.

HÖHLE, B. \& WEISSENBORN, J. Sensitivity to closed-class elements in preverbal children. A Greenhill et al. (ed.). BUCLB 22 Proceedings, p. 348-359, 1998.

HÖHLE, B. \& WEISSENBORN, J. The origins of syntactic knowledge: recognition of determiners in one-year-old German Children. Proceedings of the 24th Annual Boston Conference, 2000.

HÖHLE, B. \& WEISSENBORN, J. German-learning infant's ability to detect unstressed closed-class elements in continuous speech. Developmental Science, v. 6:2, p. 122-127, 2003.

HÖHLE, B.; WEISSENBORN, J.; KIEFER, D.; SCHULZ, A.; SCHMITZ, M. Functional elements in infants' speech processing: The role of determiners in segmentation and categorization of lexical elements. Infancy, v. 5, p. 341-353, 2004.

MAC WHINNEY, B. The CHILDES Project: Tools for analyzing talk. 3 ed. Mahawah, N J: Lawrence Erlbaum Associates, 2000. Disponível em http://childes.talkbank.org/.

MARCUS, G. F.; VIJAYAN, S.; BANDI RAO, S.; VISHTON, P. M. Rule learning by seven-month-old infants. Science, v. 283, 1999.

MINTZ, T. H. Frequent frames as a cue for grammatical categories in child directed speech. Cognition, 90, p. 91-117, 2003.

MINTZ, T. H. Finding the verbs: Distributional cues to categories available to young learners. In: K. HIRSH-PASEK \& R. M. GOLINKOFF (Eds.). Action meets word: How children learn verbs. New York: Oxford University Press, p. 31-63, 2006.

MORGAN, J \& DEMUTH, K. (Eds.) Signal to syntax: bootstrapping from speech to grammar in early acquisition. NJ: Lawrence Erlbaum Ass., 1996.

MORGAN, J.; SHI, R.; ALLOPENNA, P. Perceptual bases of rudimentary grammatical categories: toward a broader conceptualization of bootstrapping. In: MORGAN, J. \& DEMUTH, K. (Eds.) Signal to syntax: bootstrapping from speech to grammar in early acquisition. NJ: Lawrence Erlbaum Ass., 1996. 
NAME, M. C. Habilidades perceptuais e linguísticas no processo de aquisição do sistema de gênero no português. Tese (Doutorado) PUC RJ, 2002.

NAME, M. C. O que nos dizem os resultados experimentais sobre a percepção da fala pelo bebê. Veredas, Edição Especial VIII ENAL - II EIAL, 2012, p. 282-295.

NEWPORT, E. L. \& ASLIN, R. N. Learning at a distance I. Statistical learning of nonadjacent dependencies. Cognitive Psychology, nº 48(2), p. 127-162, 2004.

PEÑA, M., BONATTI, L. L., NESPOR, M., MAHLER, J. Signal-driven computations in speech processing. Science, v. 298, 2002.

RADFORD, A. Syntax: A minimalist introduction. Cambridge: UK University Press, 1997.

RODER, B. J.; BUSHNELL E. W.; SASSEVILLE A. M. Infants' preferences for familiarity and novelty during the course of visual processing. Infancy, v. 1(4), p. 491507, 2000.

SHADY, M. Infants'sensitivity to function morphemes. PhD Dissertation at Univ. Buffalo, 1996.

SHAFER, V.; SHUCARD, D.; SHUCARD, J.; GERKEN, LA. An Electrophysiological Study of Infants' Sensitivity to the Sound Patterns of English Speech. Journal of Speech, Language and Hearing Research, v. 41, p. 87 -886, 1998.

SHI, R. \& MELANÇON, A. Syntactic Categorization in French-Learning Infants. Infancy, v. 15, n. 5, p. 1-15, 2010.

SHI, R.; WERKER, J.; CUTLER, A. Function words in early speech perception. 15th ICPhS Barcelona, p. 3009-3012, 2003.

Recebido em: 10 de outubro de 2013.

Aceito em: 27 de abril de 2013. 